\title{
Understanding student radiographer attrition: Risk factors and strategies
}

Susan J McAnulla ${ }^{a}$, Susan E Ball ${ }^{b}$, Karen M Knapp ${ }^{a}$

\begin{abstract}
a Medical Imaging, College of Medicine and Health, University of Exeter, Exeter, UK
b National Institute for Health Research (NIHR) Applied Research Collaboration (ARC) South West Peninsula
\end{abstract}

Corresponding Author

Susan J McAnulla

University of Exeter

Heavitree Road

Exeter

EX1 2LU

S.J.McAnulla@exeter.ac.uk

Tel: 01392725360 
Abstract:

Introduction:

Diagnostic student radiographer attrition is reported at $14 \%, 6 \%$ higher than the average for higher education, however, little research has been undertaken on this subject. This study explored risk factors for attrition and strategies that enabled these to be overcome.

Methods:

A two-phase study was undertaken.

Phase one: data for 579 former student diagnostic radiographers (468 completers and 111 noncompleters) from 3 English universities were analysed. Logistic regression was used to estimate odds ratios and $95 \%$ confidence intervals for completion based on individual characteristics.

Phase two: content analysis of data from an online survey of 186 current UK student diagnostic radiographers exploring their experiences was undertaken.

Results:

Phase one: Attrition was 19\%. Increased age, non A-level entry qualifications and poor academic performance were predictors of attrition $(p<0.005)$.

Phase two: Challenges reported by groups identified as 'at risk' showed that for mature students and those with non-traditional entry qualifications, external responsibilities/pressures and financial pressures were likely to be the greatest cause of attrition and for younger students with traditional qualifications, academic difficulty and excessive workload were most significant. Scientific learning and academic writing were identified as the most common academic difficulties by all groups. Poor mental health may also be a risk factor.

Conclusion:

Although characteristics were identified that increased the chance of attrition, the study concluded that attrition is most likely to be multi-factorial. Academic and personal support were identified as key in students continuing their studies when they considered leaving. Clinical placement experience is likely to influence continuation decisions.

Implications for practice:

Transparency around course expectations and academic requirements together with ensuring high quality clinical placements may assist in reducing attrition.

Keywords:

Retention, Attrition, Continuation, Student radiographer, Education 


\section{Introduction}

There are approximately 27,200 diagnostic radiographers registered in the United Kingdom (UK). ${ }^{1,2}$ However the number of diagnostic radiographers working in the National Health Service (NHS) is falling at the same time as demand for imaging services is increasing. ${ }^{2-4}$ This is likely to increase pressure on service delivery and staff making it essential to retain and educate sufficient diagnostic radiographers to maintain the required workforce.

Attrition (non-completion) from diagnostic radiography degree programmes is currently reported as $14 \%$ but is as high as $44 \%$ for some UK programmes ${ }^{5}$, and the mean lies above the Department of Health (DH) target of $10 \%{ }^{6}$. Compared to $8 \%$ across Higher Education (HE) overall ${ }^{7}$, this attrition needs exploring.

Managing attrition is described as managing a 'wicked problem' where improvement can only be made when all known risk factors are managed through a proactive, sustained and systematic approach. ${ }^{8}$ This suggests the need to continually assess risk factors as these may not be consistent.

These high attrition rates together with an existing workforce shortage ${ }^{9}$ create a challenge for radiography educators; to increase the number of diagnostic radiographers entering the workforce, it would be desirable to increase the number of students enrolling but places are likely to be limited due to factors such as clinical placement availability and sufficient radiographers in imaging departments to supervise and teach students. Educators may also seek to maximise the number of students completing their training however this must be without compromise on academic, clinical or professional standards. ${ }^{10.11}$ It is therefore a responsibility of Higher Education Institutions (HEls) to provide adequate support for all students to meet these standards and enable the best possible chance of succeeding.

There is a lack of published literature relating to student radiographer attrition; the literature that is available is largely dated and although there is literature available from other healthcare professions there is a lack of comparable research for radiography. The aim of this study was to add to the limited evidence-base through exploring diagnostic student radiographer attrition. The objectives were to identify predictors of attrition (individual characteristics) and successful strategies that have prevented students from leaving. It has been acknowledged from research outside radiography education that it is difficult to predict attrition on the basis of entry characteristics alone ${ }^{12}$ and that attrition is often multi-factorial ${ }^{12-16}$; this study seeks to explore this with a view to making recommendations for good practice. 


\section{Literature Review}

Attrition rates of between $14 \%$ and $50 \%$ have been reported worldwide $e^{5,17,18}$ with academic difficulties, personal problems, wrong career choice and dissatisfaction with clinical placements identified as common reasons for non-completion. ${ }^{17-24}$

Proffit suggested that mature student diagnostic radiographers are more likely to complete their programmes than their younger counterparts ${ }^{25}$ however other authors disagree with this. Williams et al reported attrition by mature students of up to $71 \%$ and found that balancing the demands of the course with home or family life for some mature students was insurmountable and led to withdrawal. ${ }^{18,26}$

Research into admissions criteria and retention suggests that a firm foundation in mathematics and science is linked to lower attrition although no indication of the actual level of this knowledge is given. Additionally non-cognitive factors such as aptitude, clear career goals and personal experience are also reported as being important for retention. ${ }^{17,27}$ Clear career goals have been linked to good student engagement which is well-documented as being an important factor in retention with worse outcomes seen for those that did not feel connected to and supported by their programmes. ${ }^{12,18,28}$ Hawking acknowledged that students have differing motivational and psychological needs ${ }^{28}$ and this may be challenging in the clinical environment where the primary focus is likely to be on the patient. This may require both proactivity and resilience from the student in terms of maximising learning opportunity and a clear career goal and realistic expectations may help to establish this.

Despite the need to reduce attrition amongst student radiographers, it is important to recognise that some attrition is inevitable to prevent individuals unsuitable for the profession entering the workforce ${ }^{19}$ e.g. students who fail to meet the required standards of competence or conduct.

\section{Methodology}

This study adopted a pragmatic approach situated within a post-positivist paradigm to explore both the quantitative and qualitative phenomena that contributed to the outcomes or experiences of student radiographers. ${ }^{29-31}$

Ethical approval was granted by the author's University ethics committee (reference numbers 1502065 and 1802157). 
The study consisted of two phases:

Phase one: A quantitative retrospective survey of demographic and academic data from 579 student diagnostic radiographers (468 completers and 111 non-completers) from 3 English HEls who enrolled between 2009 and 2014 to establish any statistically significant associations between students' characteristics and attrition. In addition, time completed and reason for non-completion was recorded.

Data were coded according to characteristics. Entry qualifications were categorised into A-level or school-leaving qualifications (hereafter referred to as A-levels), alternative or vocational qualifications (hereafter referred to as AQs) and qualifications above academic level 3 (hereafter referred to as HEQs). Data were compared for completers and non-completers using Mann-Whitney $\mathrm{U}$ and Chi-Squared tests. Characteristics that showed statistically significant differences were included together in binary multivariable logistic regression to estimate odds ratios (OR) and 95\% confidence intervals $(\mathrm{Cl})$ for completion based on these characteristics.

Phase two: A national online survey of 186 current student diagnostic radiographers gathered quantitative and qualitative information to explore the challenges faced by student radiographers with differing characteristics that may cause them to consider withdrawing from their programme of study along with strategies used to overcome them to enable continuation of studies. It asked whether they had considered leaving and allowed them to select all applicable reasons for this. The findings from the survey were intended to provide narrative around the findings from phase one on the assumption that only students who considered leaving their programme went on to do so.

The responses were analysed using basic content analysis. ${ }^{32-34}$

\section{Results}

\section{Phase one:}

Data relating to 579 students (estimated to be $8.6 \%$ of the total diagnostic student radiographer population) were returned. An attrition rate of $19 \%$ was reported. $64 \%$ of non-completers left during academic periods, $28 \%$ during clinical placements and $8 \%$ at the end of an academic year with personal reasons being the most common cause cited (41\%). Attrition was highest during year one of programmes and occurred throughout years one and two but reduced greatly in year three. Peak 
attrition was at 12 months which reflects the period between the end of the first academic year and the beginning of the second and is likely to correspond with end of year results.

Results of Chi-squared tests and Mann-Whitney $U$ tests to identify significant differences in characteristics between completers and non-completers are shown in table 1.

Table 1. Results of statistical tests comparing characteristics of completers with non-completers.

\begin{tabular}{|c|c|c|c|c|}
\hline Characteristic & & Completers & Non-completers & $p$ value \\
\hline \multirow[t]{2}{*}{ Sex, n (\%) } & Male & $132(28)$ & $32(29)$ & \multirow[t]{2}{*}{0.90} \\
\hline & Female & $336(72)$ & $79(71)$ & \\
\hline \multicolumn{2}{|l|}{$\begin{array}{l}\text { Age on entry, median } \\
\text { (IQR) }\end{array}$} & $20(18-27)$ & $23(19-31)$ & $<0.005$ \\
\hline \multirow{4}{*}{$\begin{array}{l}\text { Highest qualification on } \\
\text { entry, } \mathrm{n}(\%)\end{array}$} & A level & $251(54)$ & $37(33)$ & \multirow[t]{4}{*}{$<0.005$} \\
\hline & $A Q$ & $65(14)$ & $31(28)$ & \\
\hline & HEQ & 135 (29) & $17(15)$ & \\
\hline & Not reported & $17(3)$ & $26(23)$ & \\
\hline \multirow{3}{*}{$\begin{array}{l}\text { Socioeconomic status, } \\
\text { n (\%) }\end{array}$} & low & $72(15)$ & $20(18)$ & \multirow[t]{3}{*}{0.18} \\
\hline & high & 227 (49) & $42(38)$ & \\
\hline & Not reported & $169(36)$ & $49(44)$ & \\
\hline \multirow{3}{*}{$\begin{array}{l}\text { Widening Participation } \\
\text { student, n (\%) }\end{array}$} & yes & $110(24)$ & $16(14)$ & \multirow[t]{3}{*}{0.22} \\
\hline & no & $241(51)$ & $23(21)$ & \\
\hline & Not reported & $117(25)$ & $72(65)$ & \\
\hline \multirow{2}{*}{$\begin{array}{l}\text { Mean academic mark, } \\
\text { median (IQR) }\end{array}$} & & $63(58-68)$ & $49(42-60)$ & \multirow[t]{2}{*}{$<0.005$} \\
\hline & $\begin{array}{l}\text { Not reported, } \\
\mathrm{n}(\%)\end{array}$ & $117(25)$ & $24(22)$ & \\
\hline
\end{tabular}


Age on entry, entry qualifications and academic marks were characteristics that demonstrated significant differences between completers and non-completers ( $p=\leq 0.05)$. ORs and $95 \% \mathrm{Cls}$ from a logistic regression model including these explanatory variables are shown in table 2.

Table 2. Odds ratios and $95 \% \mathrm{Cls}$ for completion based on characteristics.

\begin{tabular}{lll}
\hline Characteristic & OR $(\mathbf{9 5 \%} \mathrm{Cl})$ & p value \\
\hline Qualification on entry & & \\
A level qualification & Reference category & $<0.005$ \\
AQ & $0.439(0.170-1.130)$ & \\
HEQ & $0.434(0.187-1.006)$ & \\
Age on entry & $0.919(0.875-0.965)$ & $<0.005$ \\
Mean academic mark & $1.178(1.128-1.229)$ & $<0.005$ \\
\hline
\end{tabular}

The ORs indicate that the odds of completing significantly reduce with increasing age on entry, and significantly increase with increasing academic marks. The ORs for students with HEQs indicates some reduction in the odds of completing for those with these qualifications; however, the range and academic level of qualifications in the HEQ category is large, ranging from foundation degrees to PhDs so caution is required when interpreting this result. In addition, $80 \%$ students with $A Q s$ and HEQs were mature and this analysis was unable to separate age from qualifications as potential predictors of attrition.

Reasons for leaving

The distribution of reasons recorded for leaving for all non-completers is shown in table 3. 
Table 3. Frequency chart of reasons recorded for non-completion

\begin{tabular}{ll}
\hline Reason for non-completion & $\mathbf{n}(\%)$ \\
\hline Personal & $45(41)$ \\
Academic Failure & $17(15)$ \\
Unsuited to course & $15(14)$ \\
Deemed withdrawn & $11(10)$ \\
Medical & $7(6)$ \\
Transfer programme & $5(4)$ \\
Financial & $3(3)$ \\
Other & $2(2)$ \\
Expulsion & $1(1)$ \\
Not reported & $5(4)$ \\
\hline
\end{tabular}

The reasons for leaving were compared between groups according to characteristics identified as significant in phase one.

Age

There were differences in the prevalence of reasons given for leaving between mature students (defined by The Office for Students (OfS) as being over the age of 21 years on enrolment ${ }^{35}$ ) and 1721 year olds as illustrated in Table 4. 
Table 4. Number of students in each age category leaving for each reason.

\begin{tabular}{ccc}
\hline $\begin{array}{c}\text { Reason for leaving ( } \mathbf{n}, \% \text { total } \\
\text { attrition) } \\
\text { Medical }\end{array}$ & Mature & Age category \\
Personal & $4(4)$ & $3(3)$ \\
Financial & $33(30)$ & $12(11)$ \\
Academic Failure & $3(3)$ & 0 \\
Transfer course & $8(7)$ & $9(8)$ \\
Unsuited to course & $1(1)$ & $4(4)$ \\
Deemed withdrawn & $4(4)$ & $11(10)$ \\
Expulsion & $7(6)$ & $4(4)$ \\
Other & $1(1)$ & 0 \\
Missing data & $1(1)$ & $1(1)$ \\
\end{tabular}

The highest attrition was from mature students and for personal reasons. The majority of students leaving for reasons that might be considered 'changing their minds' i.e. transfer programme and being unsuited to the course were in the 17-21 age group. The raw data showed that all students leaving for financial reasons were over 37 years of age.

Entry qualification

Table 5 demonstrates the numbers of students leaving for each reason within each entry qualification category. The highest attrition was from students with AQs and for personal reasons. 
Table 5. Number of students with each entry qualification leaving for each reason.

\begin{tabular}{ccccc}
\hline & \multicolumn{4}{c}{ Entry Qualification } \\
\hline $\begin{array}{c}\text { Reason for leaving }(\mathrm{n}, \% \\
\text { total attrition) } \\
\text { Medical }\end{array}$ & A level & AQ & HEQ & Not stated \\
Personal & $3(3)$ & $2(2)$ & $2(2)$ & 0 \\
Financial & $12(11)$ & $16(14)$ & $6(5)$ & $11(10)$ \\
Academic Failure & 0 & $2(2)$ & $1(1)$ & 0 \\
Transfer course & $3(3)$ & $5(5)$ & $3(3)$ & $4(4)$ \\
Unsuited to course & $3(3)$ & $2(2)$ & 0 & 0 \\
Deemed withdrawn & $11(10)$ & $1(1)$ & $2(2)$ & $1(1)$ \\
Expulsion & 0 & $3(3)$ & $2(2)$ & $6(5)$ \\
Other & 0 & 0 & 0 & $1(1)$ \\
Missing data & 0 & 0 & 0 & $2(2)$ \\
\hline
\end{tabular}

\section{Academic performance}

Table 6 demonstrates the numbers of students within each academic performance category leaving for each reason.

Table 6. Number of students within each academic mark category leaving for each reason.

\begin{tabular}{ccccccc}
\hline & \multicolumn{5}{c}{ Mean academic mark } \\
\hline $\begin{array}{c}\text { Reason for leaving ( } \mathbf{n}, \\
\text { \% total attrition) }\end{array}$ & $<40 \%$ & $40-49.5 \%$ & $50-59.5 \%$ & $60-69.5 \%$ & $>69.5 \%$ & Not stated \\
Medical & $1(1)$ & 0 & $2(2)$ & $2(2)$ & $1(1)$ & $1(1)$ \\
Personal & $7(6)$ & $14(13)$ & $5(5)$ & $8(7)$ & $3(3)$ & $8(7)$ \\
Financial & 0 & $1(1)$ & $2(2)$ & 0 & 0 & 0 \\
Academic Failure & $4(4)$ & $6(5)$ & $2(2)$ & $2(2)$ & 0 & $3(3)$ \\
Transfer course & 0 & $1(1)$ & $1(1)$ & 0 & $1(1)$ & $2(2)$ \\
Unsuited to course & 0 & $2(2)$ & $3(3)$ & $2(2)$ & $2(2)$ & $6(5)$ \\
Deemed withdrawn & 0 & $6(5)$ & $2(2)$ & 0 & $2(2)$ & $1(1)$ \\
Expulsion & 0 & 0 & $1(1)$ & 0 & 0 & 0 \\
Other & $1(1)$ & 0 & $1(1)$ & 0 & 0 & 0 \\
Missing data & 0 & 0 & 0 & 0 & 0 & 5 \\
\hline
\end{tabular}


The highest attrition was from students achieving $40-49.5 \%$ and for personal reasons. Not all students recorded as leaving due to academic failure had low mean academic marks.

\section{Phase two:}

186 responses were received representing an estimated response of $5 \%$. There were no significant differences in the characteristics of the participants compared to the phase one data other than entry qualifications. A-level was the majority qualification in phase one and $A Q$ the majority in phase two ( $p<0.005)$. Qualitative responses varied from 2 to 746 (mean 80) words for individual questions. 101 respondents (54\%) indicated that they had considered leaving their programmes with all but 10 citing multiple reasons. Academic difficulty, financial difficulty and personal problems were the most prevalent at $17 \%, 16 \%$ and $16 \%$ respectively. Dissatisfaction with clinical placements and ill health were the next most common at $13 \%$.

Basic content analysis of the free text responses resulted in six key themes as shown in table 7. 
Table 7. Illustration of themes from content analysis

\begin{tabular}{|c|c|c|c|c|c|}
\hline Tiredness & Independent & Loneliness & Negative & Loss of income & III Health \\
\hline Placement & learning & Fitting in & experience with & Mature student & Stress \\
\hline hours & Academic & Leaving home/ & radiographers & issues & Asking for help \\
\hline Working & writing & independent & Patients & Carer & \\
\hline alongside & Academic & living & Missing out on & responsibilities & \\
\hline degree & level/difficulty & Feeling & student life & Returning to & \\
\hline \multirow{11}{*}{$\begin{array}{l}\text { Work-life } \\
\text { balance }\end{array}$} & Academic & unprepared & Placements - & being a student & \\
\hline & assessment & Different from & distance/ & Financial & \\
\hline & Revision & school & travel & pressure & \\
\hline & Relevance of & Relationships & Placement & Commuting & \\
\hline & degree & with lecturers & integration & & \\
\hline & & Meeting & Placement & & \\
\hline & & professional & learning/ & & \\
\hline & & standards & competency & & \\
\hline & & & Short holidays & & \\
\hline & & & Working for & & \\
\hline & & & free & & \\
\hline \multirow[t]{3}{*}{ WORKLOAD } & ACADEMIC & ADJUSTING TO & POOR CLINICAL & BEING A & HEALTH \\
\hline & DIFFICULTY & UNIVERSITY & PLACEMENT & MATURE & \\
\hline & & & EXPERIENCE & STUDENT & \\
\hline
\end{tabular}

\section{Excessive Workload}

Many students struggled to balance academic learning with assessments and clinical placements.

"Juggling the number of modules and assignments while also on placement. It's a great deal of stress, and I believe placement should run alone with students just completing their portfolio and appraisals. Especially in hospitals that students work shifts." (P167) 
"Balancing exams, assignments, and placement, while still finding time for personal life." (P133)

"Time management to balance placement and other university work has always been a challenge. It can get stressful at times." (P165)

Managing workload was perceived to be more of a challenge for younger students than mature students; however more mature students considered leaving because of it. Respondents indicated that keeping on top of revision and support from others (family, friends and academics) were the strategies that allowed them to overcome this difficulty.

\section{Academic difficulty}

Excessive workload and academic difficulty were often entangled in responses however students in all groups reported finding the scientific elements of their programmes and academic writing most difficult. Despite all entering with acceptable qualifications, several felt that they lacked the skills needed.

"Finding and using literature for the assignments, I had never referenced anything before." (P125, aged 18, A levels)

"My Academic skills were non-existent before completing the access course, I have found essay writing and research difficult to learn." (P145, aged 42, AQ),

"I came from a BTEC background. The most surprising thing for me and probably the toughest was for me to get a grasp of academic writing. My BTEC course was assignment based and I came out with distinctions across the board. However, when it came to my 1st assignment towards the end of 1st year I got a massive shock..." (P146, aged 19, AQ),

"I think it would have been my lack of knowledge in physics, my access to higher education course did not include any physics and I had no past experience of physics whatsoever." (P85, aged 39, AQ),

"The physics aspect was difficult as I had not done it since GCSE level." (P101, aged 22, HEQ.) Academic writing was more often mentioned by younger students than mature students and when responses were considered by entry qualification this was identified as challenging for students in all 
categories although only one comment came from a student with previous HE experience. This may be indicative of a general challenge for students transitioning into HE.

Difficulty with the scientific aspects of the programme was twice as prevalent in the comments from students with AQs and HEQs as those with A levels.

Peer and academic support were identified as the strategies than enabled continuation.

Difficulties adjusting to university

$71 \%$ comments relating to difficulty adjusting to university came from $17-21$ year olds and $58 \%$ of these had considered leaving citing mainly academic difficulty or personal problems. When examined more closely, these comments related to adjusting to a different style of learning compared to school or college and social factors such as living independently for the first time.

"Moving away from home and sorting out my finances in order to support my studies" (P24, aged 19)

"Juggling placement and all University responsibilities such as exams and domesticated things like cooking and washing" (P62, aged 19)

"It was difficult to be responsible for your learning 100\%, there is no one at university who will chase things up and constantly remind you about deadlines." (P81, aged 19)

Additionally three students commented on lack of clear expectations;

"I think understanding the nature of the profession as a whole. I only really understood our roles during a second year placement. Therefore, placement was the suggest [sic] factor in overcoming this." (P153, aged 18)

"...expectations of the level of professionalism in and outside of university. The pressure of those expectations was the challenge." (P77, aged 18)

"The idea of being a 'professional' and the idea of a wide community of healthcare professionals with so much knowledge was very intimidating and I was very unsure if I would ever be able to reach 'their level'' (P110, aged 19) 
$50 \%$ mature students had considered leaving due to difficulty adjusting to university but the reasons given differed from the younger students; financial difficulties, ill health and personal problems were most prevalent. Academic aspects of returning to education and adjusting from being a 'worker' to being a 'learner' in an unfamiliar environment along with fear of not fitting in with younger students were mentioned.

"Going from a full time job where I was training students, to being a student knowing nothing about what I was doing." (P65, aged 23)

"Teaching myself how I learn again" (P75, aged 27)

"Having been in the field of teaching prior to commencing my radiography degree, the biggest challenge was becoming a student again... there was also the fear of not fitting in with the younger students." (P104, aged 37)

The majority of comments relating to adjusting to university were made by students with A levels which is likely to be reflective of their younger age.

\section{Poor clinical placement experience}

Clinical placements were the most commonly mentioned challenge across all respondents. $56 \%$ of the comments were made by $17-21$ year olds compared with $44 \%$ by mature students. This is approximately reflective of the age group proportions within the dataset so suggests that this challenge is no more common for either group. $56 \%$ of the younger students mentioning clinical placements had considered leaving compared with $64 \%$ of the mature students suggesting that poor clinical placement experience may be slightly more influential for mature students in terms of discontinuation decisions. Multiple aspects of placements were mentioned by both age groups including travel/distance, isolation, long hours leading to tiredness and lack of opportunity to earn money, financial costs associated with placements e.g. additional childcare/accommodation/travel, difficulty in dealing with patients, dissatisfaction with having to move away from university to attend placement, lack of time for academic work and poor support from clinical and academic staff. For the younger students, missing out on 'traditional student life' was also mentioned.

A number of comments identified poor behaviour from radiographers towards students as challenging; 
"Placement - handling negative behaviour of some qualified radiographers towards students. Fear of raising issues for potential effect on future career." (P67)

"a small but significant majority of clinical staff on placement made it a very alienating experience, through 'cliques', department culture, poor management, poor organisation, and general lack of interest in students, to the point where I'm not sure I want to complete the degree." (P102)

Participant 102 also expressed dissatisfaction with the manner in which their concerns were addressed;

"...university staff have largely said 'that's just the way it is'."

The coping strategies demonstrated determination in spite of poor experience;

"Just keep trying to be proactive and not lose hope even if they didn't want to interact with you" (P167)

“...put bullying into perspective." (P67)

However, radiographers were recognised as a source of positive support by others:

"Having a member of staff on practice that you could work with, learn from and ask silly questions to was so helpful. It let me learn without having to learn through mistakes." (P169)

"Placement is where you get the most support" (P56)

Three students indicated that they actively sought out particular radiographers to work with.

"Placement can be either totally amazing or totally awful depending on the rota. Certain radiographers or departments can leave you thinking "why am I doing this?" I remind myself it's just a day or a week and to remember not to be like that when I'm qualified. Or that I wouldn't work in that department." (P97)

\section{Being a mature student}

$49 \%$ respondents were mature students ( $62 \%$ of these were over 26 years of age). $56 \%$ mature students had considered leaving compared with 53\% 17-21 year olds. All but two cited multiple reasons. Many of the challenges identified by mature students related to external factors such as 
financial pressures and juggling other responsibilities alongside their studies. Two powerful comments illustrated how complex some students' circumstances can be;

"The change to my life style from being a [part time] factory worker and stay at home mum...a husband working away to all of my free time being taking up with work experience...to adjust to the new routine and miss important celebrations of my children's education... Also financially trying to continue to work has been near on impossible but requiring childcare with no financial help so I can attend education and placement. Most weeks pass I do not get one day off. This is mainly placement that does not take our circumstances of life into consideration mainly expecting us to work around them...I understand when employed this would be normal, but we are not paid at the moment and need to work to pay childcare to be on placement.... A forced house move is causing massive problems...and a very poorly dependant [relative]...is causing more strain and pressure and very little free time. These are all issues that make me want to either quit my part time job, my radiography or both." (P129).

"No money, childcare responsibilities, no connection to other students, loneliness, strain on my relationship, grieving...anxiety, depression." (P109)

Long commutes from their homes to clinical placements were also problematic for some. It was clear that most of the mature students were committed to their studies, willing to support themselves and reluctant to become financially dependent on others. Strategies such as taking on part-time employment, financial support from partners or returning to live with parents in order to manage debt were mentioned as being necessary in facilitating their continuation.

III Health

Although ill health was one of the least prevalent themes with 39 comments, 37 of these were from students who had considered leaving. There was a slight over-representation from mature students and those with AQs. The vast majority of the comments related to mental health. It appeared that for most of the students mentioning ill health, the impact of other circumstances on their health was the main reason they chose this as a reason for considering leaving. 


\section{Entry Qualifications}

In addition to the emergent themes, in response to entry qualifications being identified as a significant risk factor, responses were grouped according to entry qualifications and compared to explore whether any issues were more commonly reported by students from a particular group. This was not demonstrated to be the case.

\section{Discussion, conclusions and recommendations}

The study was limited by the dataset available; the response rates for both phases were low and only three universities were represented in the phase one data and therefore the findings may not be more widely generalisable.

The study identified poor academic performance, increased age on entry and AQs or HEQs as risk factors for attrition thus meeting one of the objectives. However, it was not possible from the data acquired to disentangle age from qualifications which is a further limitation of this study. A larger dataset may have provided improved granularity and further research into this would be recommended.

The survey suggested that mature students with AQs or HEQs were most challenged by conflicting responsibilities whereas younger student with the same qualifications were most challenged by academic factors. Some consideration as to whether these AQs are suitable alternatives to A-levels for entry to Diagnostic Radiography degrees by school leavers might be appropriate. Mature students may gain additional skills through employment and experience that are beneficial in addition to their $A Q$ for success. This study supported the suggestion that students with a firm scientific and mathematical background were less likely to leave due to academic difficulty ${ }^{17,27}$ but additionally highlighted a perceived lack of academic writing skills. Educators may consider offering enhanced guidance and tuition to assist students in developing these skills early in their programmes to reduce the risk of academic failure due to poor writing.

Based on the estimated ORs, poor academic performance whilst enrolled may be the greatest single predictor of attrition however it is not a pre-existing characteristic and may be a symptom of an underlying problem. Close monitoring of academic performance could aid early identification of a student encountering difficulties and enable intervention before they escalate and result in attrition. It is recommended that the reality and requirements of undertaking a diagnostic radiography degree 
are transparent to prospective students at the point of application; this may facilitate thorough consideration regarding the decision to pursue this with all other demands taken into account; it is likely that academic performance would be impacted if a student is managing conflicting pressures. Additionally, a more flexible approach to physical attendance may be beneficial for some if the learning outcomes can be achieved in a way that allows students to fit some of their studies around their commitments whilst maintaining engagement and belonging.

This study found that although only 7 students in phase 1 left due to ill health, comments from phase 2 suggest that mental health difficulties are likely to be the greatest health-risk in terms of attrition. An estimated $17 \%$ of the UK population suffer from a mental health related episode every week with the highest prevalence amongst women aged 16-24 years. ${ }^{36}$ The majority of students in this survey fell within this age range. From the participants' comments, there was a clear message that impact on mental health, even in the absence of a diagnosed condition will lead some students to consider leaving. However, several responses indicated that if appropriate academic and personal support was received, continuation was possible.

The majority of attrition due to students changing their minds about their course was seen in younger students. Therefore there is some consideration to be given regarding the information upon which students make the decision to apply for radiography programmes. There may be scope to improve careers advice and a need for realistic expectations to be set, preferably prior to enrolment.

This study identified clinical placement experience as influential in continuation decisions so it is important for both students and clinical staff to have clear expectations of what constitutes a high quality clinical placement and for clinical staff to understand the influence that they may have on student retention. It is important that universities and clinical placement providers acknowledge a shared responsibility for placement quality and that unsupportive or unprofessional behaviour from clinical staff towards students is not tolerated; the existing workforce shortage will not be reduced without training students.

The study also set out to add to the limited evidence base on this subject. The findings from this study are largely in agreement with the existing evidence base so it is suggested that although the literature may be dated, it is likely to remain appropriate and findings from other professions' attrition research are likely to be relevant to diagnostic radiography.

To conclude, this study met its objectives in terms of identifying potential risk factors for attrition and provided some insight into how students responded successfully to the challenges they faced. 
In addition it has provided information that may help in understanding how continuation decisions might be influenced. Strategies such as external support (both personal and academic) were widely identified in the survey as being essential in enabling students to continue so educators are encouraged to consider the findings from this study in planning and provision of student support.

From the findings of this study the following recommendations are made:

- University admissions information includes the time commitment required and clinical placement requirements of the programme.

- Universities and clinical placement providers work in close partnership to support students during clinical placements.

- Reports of poor behaviour of clinical radiographers towards students are taken seriously and addressed.

- Students have access to appropriate support networks both within the academic and clinical settings.

- Students are encourage to disclose any difficulties they are having and supportive conversations held to assist in developing coping mechanisms.

- There is adequate support for student wellbeing.

- Regular monitoring of academic progress is undertaken e.g. early and regular formative assessments with rapid access to remediation if required. 


\section{References}

1. NHS Digital. [Internet]. Diagnostic radiographer. 2019 [cited 09/04/19]; Available from: https://www.healthcareers.nhs.uk/explore-roles/allied-health-professionals/roles-alliedhealth-professions/diagnostic-radiographer.

2. NHS Digital. [Internet]. NHS workforce statistics - December 2018. 2019 [cited 09/04/19]; Available from https://digital.nhs.uk/data-and-information/publications/statistical/nhsworkforce-statistics/december-2018

3. Royal College of Radiologists. UK workforce census 2017 report. 2017. p. 23. [cited 09/04/19]; Available from https://www.rcr.ac.uk/system/files/publication/field_publication_files/bfcr185_cr_census_2 017.pdf

4. NHS Digital. [Intenet]. NHS Workforce Statistics in England, Non-medical staff - 2004-2014, As at 30 September. 2015 [cited 08/10/15]; Available from: http://www.hscic.gov.uk/catalogue/PUB16933.

5. Society and College of Radiographers. College of Radiographers Approval and Accreditation Board Annual Report 2016-17. 2017 [cited 26/10/18]; Available from: https://www.sor.org/sites/default/files/document-versions/cor_aab_annual_report_20162017.pdf

6. Department of Health. Education Commissioning: Synopsis of the outcomes of the Action Learning Sets Project Studying Pre Registration Attrition November 2008 - December 2009. 2009 [cited 31/01/16]; Available from:

http://www.skillsforhealth.org.uk/search/education\%20commissioning/?ordering=newest\& searchphrase=all.

7. Higher Education Statistics Agency. Non-continuation: UK Performance Indicators 2017/18. 2019 [cited 09/04/10]; Available from: https://www.hesa.ac.uk/news/07-03-2019/noncontinuation-tables.

8. Department of Health. Student Nurses and Midwives: A Guide to Good Practice for Strategic Health Authorities and Higher Education Institutions, 2006 [cited 24/04/15]; Available from: http://webarchive.nationalarchives.gov.uk/20080905235643/dh.gov.uk/en/Publicationsand statistics/Publications/PublicationsPolicyAndGuidance/DH_073230

9. UK Visa Bureau. [Internet]. UK shortage occupations list. 2018 [cited 16/12/18]; Available from: http://www.visabureau.com/uk/shortage-occupations-list.aspx\#healthcare. 
10. Duffy, K. Failing Students. 2003 [cited 13/07/17]; available from https://www.researchgate.net/profile/Kathleen_Duffy/publication/251693467_Failing_Stud ents_A_Qualitative_Study_of_Factors_that_Influence_the_Decisions_Regarding_Assessmen t_of_Students'_Competence_in_Practice/links/5644f3c508ae54697fb8475e.pdf

11. Health and Care Professions Council. Standards of Education and Training. 2017: London.

12. Thomas, L. Building student engagement and belonging in Higher Education at a time of change: final report from the What Works? Student Retention \& Success programme. 2012 [cited 10/04/19]. Higher Education Academy. Available from:

https://www.heacademy.ac.uk/knowledge-hub/building-student-engagement-andbelonging-higher-education-time-change-final-report

13. Maher, B, Hynes, H, Sweeney, C, Khashan, A, O’Rourke, M, Doran, K, et al. Medical School Attrition-Beyond the Statistics A Ten Year Retrospective Study. BMC Medical Education, 2013. 13(1): p. 13.

14. Cameron, J, Roxburgh, M, Taylor J, Lauder, W. An integrative literature review of student retention in programmes of nursing and midwifery education: why do students stay? Journal of Clinical Nursing, 2011. 20(9/10): p. 1372-1382.

15. Orton, S. Re-thinking attrition in student nurses. Journal of Health and Social Care Improvement, 2011(February): p. 1-7.

16. Hamshire, C., Willgoss, T.G.,Wibberley, C. 'The placement was probably the tipping point' The narratives of recently discontinued students. Nurse Education in Practice, 2012. 12(4): p. 182-186.

17. Kudlas, M. Effects of Radiography Program Admissions Practices on Student Retention. Journal of Allied Health, 2006. 35(October (fall)): p. 162-168.

18. Gillis, C. Leaving seats empty: Exploring student attrition in an undergraduate health sciences program. 2008, Mount Saint Vincent University (Canada): Ann Arbor. p. 111.

19. McNamara, J. The recruitment and retention of therapy radiographers. International Journal of Therapy \& Rehabilitation, 2010. 17(5): p. 225-225.

20. Society and College of Radiographers. Analysis of student and recently qualified radiographer survey results 2009 [cited 14/10/15]; Available from: http://www.sor.org/learning/document-library/survey-students-and-recent-graduates$\underline{2009}$.

21. Society and College of Radiographers. Analysis of student and recently qualified radiographers survey 2010 [cited 14/10/15]; Available from: 
http://www.sor.org/learning/document-library/analysis-students-and-recent-graduatessurvey-2010.

22. Society and College of Radiographers. Analysis of student and recently qualified radiographers survey 2011. 2011 [cited 2015 14/10/15]; Available from: http://www.sor.org/learning/document-library/analysis-students-and-recent-graduatessurvey-2011.

23. Society and College of Radiographers. Analysis of student and recently qualified radiographers survey 2014. 2014 [cited 14/10/15]; Available from:

http://www.sor.org/learning/document-library/analysis-student-and-recently-qualifiedradiographers-survey-2014.

24. Society and College of Radiographers. Analysis of students and recent graduates survey 2012. 2012 [cited 14/10/15]; Available from: http://www.sor.org/learning/documentlibrary/analysis-students-and-recent-graduates-survey-2012-0.

25. Proffitt, R.E. An assessment of associate degree radiography programs in Virginia: Comparison between traditional and nontraditional students. 1998, East Tennessee State University: Ann Arbor. p. 138.

26. Williams, M. and Decker, S. Mature students' perspectives of studying radiography. Radiography, 2009. 15(1): p. 77-85.

27. Ingrassia, J.M. Successful Admission Criteria to Predict Academic and Clinical Success in Entry-Level Radiography Programs. Radiologic Technology, 2016. 87(5): p. 502-510.

28. Hawking, N. Teaching and the profession. Effective communication affects student achievement and retention. Radiologic Technology, 2005. 76(3): p. 234-236.

29. Polgar, S., Thomas, S, Introduction to Research in the Health Sciences. 6 ed. 2013, Edinburgh: Churchill Livingstone.

30. Panhwar, A., Ansari, S, and Shah, A. Post-positivism: an effective paradigm for social and educational research. International Research Journal of Art \& Humanities, 2017. 45(45): p. 253-259.

31. Clark, A.M. The qualitative-quantitative debate: moving from positivism and confrontation to post-positivism and reconciliation. Journal of Advanced Nursing, 1998. 27(6): p. 12421249.

32. Erlingsson, C., Brysiewicz, P. A hands-on guide to doing content analysis. African Journal of Emergency Medicine, 2017. 7: p. 93-99.

33. Drisko, J.W., Maschi, T. Basic Content Analysis, in Content Analysis. 2015, Oxford University Press: New York. p. 25,26. 
34. Weber, R. Basic Content Analysis. 1990, SAGE Publications, Inc.: Thousand Oaks, California. p. 22.

35. Office for Students. Mature and part-time students. no date [cited 02/07/19]; Available from https://www.officeforstudents.org.uk/media/3da8f27a-333f-49e7-acb3841feda54135/topic-briefing_mature-students.pdf

36. Baker, C. Mental health statistics for England: prevalence, services and funding. 2018 [cited 21/06/19]. House of Commons Library. Available from https://researchbriefings.files.parliament.uk/documents/SN06988/SN06988.pdf

Funding Source Declaration:

This study was funded by The University of Exeter.

Susan Ball is funded by the National Institute for Health Research (NIHR) Applied Research Collaboration (ARC) South West Peninsula. The views expressed are those of the authors and not necessarily those of the NHS, the NIHR or the Department of Health and Social Care.

Keywords: Retention; Attrition; Continuation; Student radiographer; Education. 